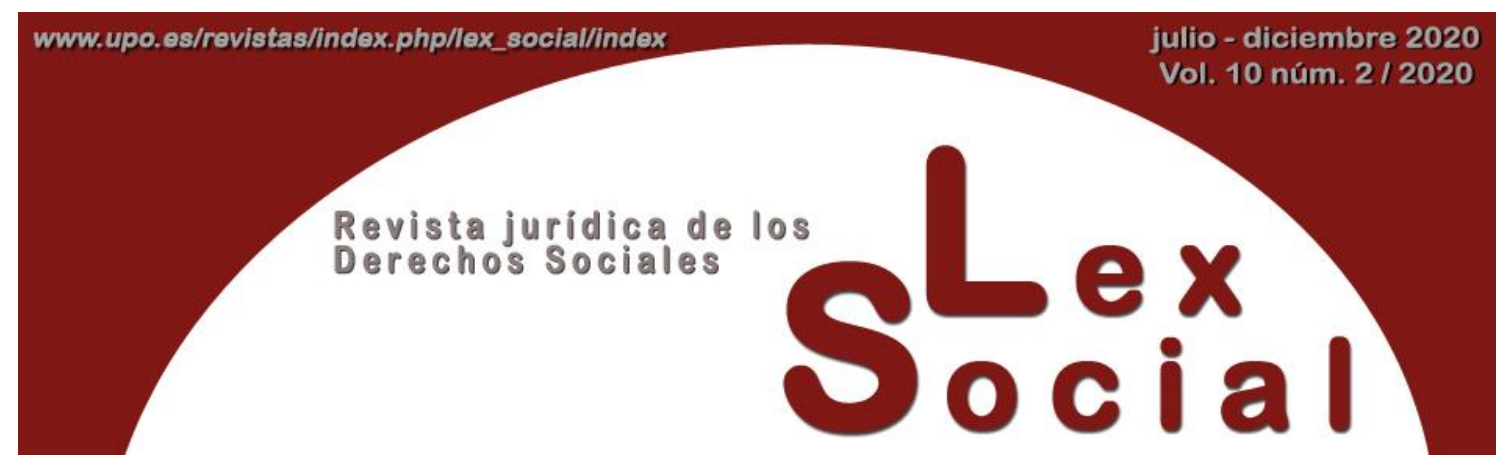

\title{
PRESENTACIÓN
}

\section{EL CUMPLIMIENTO DE LAS NORMAS INTERNACIONALES DEL TRABAJO POR LAS EMPRESAS MULTINACIONALES: ENTRE LO DESEABLE Y LO POSIBLE}

\author{
JOSÉ LUIS GIL Y GIL \\ TATSIANA USHAKOVA \\ Universidad de Alcalá
}

DOI: https://doi.org/10.46661/lexsocial.5058

La primera parte del volumen 10, número 2, de Lex Social, Revista jurídica de los derechos sociales, incorpora una selección de estudios de autores españoles y extranjeros de gran prestigio en el ámbito del Derecho internacional y europeo del trabajo, que han participado en el proyecto de investigación Empresas multinacionales y normas internacionales del trabajo. Especial referencia a la situación en España (DER201677973-R), financiado por el Ministerio de Economía y Competitividad durante los años 2016 a 2019, y del que ha sido investigador responsable José Luis Gil. Muchos de los miembros del proyecto forman parte, además, del grupo de investigación consolidado de la Universidad de Alcalá Estándares laborales y comercio global, que la Universidad de Alcalá ha clasificado como de alto rendimiento. El proyecto prosigue la línea de investigación de los proyectos La respuesta de la OIT ante la crisis económica: orientaciones para las políticas internacionales y nacionales para impulsar la recuperación, con especial referencia a la política nacional española [DER2010-17767 (Subprograma JURI)] y Comercio y justicia social en un mundo globalizado, con especial referencia a los intereses de España (DER2013-47698-R).

Los trabajos se han presentado y discutido en dos seminarios internacionales, celebrados en la Universidad de Alcalá los días 21 de mayo de 2018 y 16 de diciembre de 2019: el primero llevaba por título Empresas multinacionales y derechos humanos: puntos de conexión, y el segundo, Responsabilidad de las empresas multinacionales por Lex Social, vol. 10, núm. 2 (2020) 
vulneración de los estándares laborales: Entre lo deseable y lo posible. En el primer seminario, se abordó el tema desde una perspectiva general y panorámica. Como es bien sabido, la posición de las empresas multinacionales en el plano internacional es objeto de una gran polémica. Por un lado, son entes que acumulan un enorme poder económico, que supera, con frecuencia, al de los Estados. Por otro lado, no pueden responder directamente por la vulneración de los derechos humanos, en particular los derechos laborales. En este sentido, las empresas multinacionales se hallan sujetas a la legislación de los Estados en cuyo territorio desarrollan su actividad, o cuyos nacionales emplean. Esta paradoja se puso de relieve, en especial, a partir de los años 70, en que surgieron numerosos estudios sobre el concepto y el papel de las empresas multinacionales en el Derecho internacional. A esos años ya lejanos, remiten los debates prolíficos e interminables sobre la personalidad jurídica internacional de las empresas. Desde entonces, y como respuesta a la imposibilidad de que las empresas respondan en el plano internacional, surgieron varios instrumentos de soft law. Sin duda, el más destacado y analizado se denomina Principios Rectores sobre las empresas y los derechos humanos: puesta en práctica del marco de las Naciones Unidas para "proteger, respetar y remediar”, de 2011, anexo al Informe del Representante Especial del Secretario General de la ONU para la cuestión de los derechos humanos y las empresas transnacionales y otras empresas, John Ruggie (UN Doc. A/HRC/17/31). El Consejo de Derechos Humanos hizo suyos los Principios Rectores en su Resolución 17/4, de 16 de junio de 2011. Entre sus antecedentes, muchos de los cuales se han revisado recientemente, cabe mencionar: las Normas sobre las responsabilidades de las empresas transnacionales y otras empresas comerciales en la esfera de los derechos humanos, elaboradas por la Comisión de Derechos Humanos de la ONU en 2003; las Líneas Directrices de la Organización para la Cooperación y el Desarrollo Económico (OCDE) sobre las empresas multinacionales, actualizadas en 2011; la Declaración Tripartita de Principios sobre las Empresas Multinacionales y la Política Social de la Organización Internacional del Trabajo, revisada en 2017, y el Pacto Global de la ONU, de 2000, el instrumento sobre la responsabilidad social corporativa más relevante en el plano internacional universal. En el segundo seminario, se volvió a hacer un balance de esos instrumentos y, además, se profundizó en el tema de la responsabilidad de las empresas, a la luz de dos hechos recientes de mucha relevancia: la elaboración de un instrumento jurídicamente vinculante en el marco de la ONU y las iniciativas nacionales relacionadas con el deber de diligencia (due diligence) de las empresas, como, por ejemplo, la Ley 2017-399, de 27 de marzo de 2017, promulgada en Francia, que contempla el deber de vigilancia para las empresas, filiales, subcontratas y otros socios comerciales.

En esta línea de ideas, las contribuciones al presente número monográfico incluyen tanto estudios sobre los instrumentos adoptados en los planos internacional y regional, como análisis de la práctica y las propuestas legislativas en los países europeos. El número se abre con un estudio general del profesor Gil y Gil, el investigador principal del proyecto, que sigue el marco conceptual de los Principios Rectores, y examina el deber del Estado de proteger los derechos humanos en el trabajo, el deber de las empresas multinacionales 
de respetarlos y el derecho de los trabajadores a medidas de reparación adecuadas. A continuación, el profesor Servais reflexiona, con carácter general, sobre la regulación social transnacional de las empresas multinacionales, y lleva a cabo algunas sugerencias para paliar las consecuencias sociales negativas de la globalización. La investigadora postdoctoral Fernández Martínez, a quien agradecemos su ayuda en la celebración del segundo seminario, se ocupa de las Líneas Directrices de la OCDE para empresas multinacionales, y el profesor Carby-Hall, de las empresas multinacionales y el Global Compact. La profesora Ushakova estudia la situación de las empresas, y en particular las multinacionales, en el sistema del Consejo de Europa, en especial los aspectos relacionados con la responsabilidad de las empresas y la práctica del TEDH al respecto. La contribución del profesor Auvergnon trata de la responsabilidad de las empresas multinacionales desde la perspectiva del Derecho francés, y es muy importante para apreciar las luces y las sombras que suscita la mencionada ley francesa en el debate la obligación de due diligence. El profesor Ferrante presenta una aproximación al estado de cuestión en el panorama jurídico italiano, y el profesor Seifert, en el Derecho alemán. En fin, el profesor Del Valle hace un análisis exhaustivo de las empresas multinacionales en relación con los problemas de la Seguridad Social. Nuestro agradecimiento a los autores, por su participación en el proyecto y en los seminarios y por la calidad de sus trabajos, y a Carmen Salcedo, por haber aceptado la publicación y por su ayuda y paciencia en el proceso de envío de los originales. 